\title{
OPTIMIZATION OF SHIP SPEED AND FLEET DEPLOYMENT UNDER CARBON EMISSIONS POLICIES FOR CONTAINER SHIPPING
}

\author{
Yuwei XING, Hualong YANG*, Xuefei MA, Yan ZHANG \\ Transportation Engineering College, Dalian Maritime University, Dalian, China
}

Received 16 October 2017; revised 1 February 2018; accepted 30 June 2018

\begin{abstract}
In this paper, under the consideration of two carbon emissions policies, the issues of optimizing ship speed and fleet deployment for container shipping were addressed. A mixed-integer nonlinear programming model of ship speed and fleet deployment was established with the objective of minimising total weekly operating costs. A simulated annealing algorithm was proposed to solve the problem. An empirical analysis was conducted with the data selected from the benchmark suite. The applicability and effectiveness of the established model and its algorithm are verified by the results. According to the results, two policies of the cap-and-trade programme and the carbon tax can better optimize the results of the ship speed and fleet deployment problem to achieve the goal of reducing carbon emissions. The research remarks in this paper will provide a solution for container shipping companies to make optimized decisions under carbon emissions policies.
\end{abstract}

Keywords: ship speed, fleet deployment, non-linear programming, cap-and-trade programme policy, carbon tax policy, simulated annealing algorithm.

\section{Introduction}

Container shipping plays an important role in the shipping industry due to its reliable and regular service to ports along routes (Wang et al. 2013b). Containerships have become larger because the container shipping companies aim to take advantage of the economics of scale. Therefore, it is important for a container shipping company to assign containerships to port rotations in an efficient manner to transport containers (Wang, Meng 2017). This decision problem is referred to as the Fleet Deployment Problem (FDP). The FDP was first addressed in the literature by Perakis and Jaramillo (1991) and Jaramillo and Perakis (1991). The researchers established (integer) linear programming models for the planning problem. Considering the changes in container shipping demand, Meng and Wang (2010) extended their study and suggested that container shipping demand obeys a normal distribution. Because complete probability distributions are hard to obtain in practice, $\mathrm{Ng}$ (2015) proposed a new distributionfree optimization model that only requires the specification of the mean, standard deviation and an upper bound of the container shipping demand. These studies make the study of the FDP more realistic.

Data show that fuel costs accounts for approximately three quarters of a large containership's operating costs when the bunker fuel price is approximately $500 \$ /$ ton (Ronen 2011). The fuel consumption cost of a containership is a nonlinear convex function with respect to the ship speed (Gelareh, Meng 2010). Therefore, when the fuel market fluctuates, the container shipping company usually chooses to implement a speed adjustment strategy to reduce their costs. Ronen (2011) set costs minimization as a goal and studied methods for determining ship speed and fleet size. Notteboom and Vernimmen (2009) investigated the optimal uniform speed on a single ship route. Gelareh and Meng (2010) discussed the model development for a short-term FDP of container shipping operations, in which the optimal ship speeds are interpreted as their realistic optimal travel times. These studies have significantly contributed to the development of mathematical programming models of ship speed and fleet deployment optimizations.

In recent years, the issue of global climate change caused by carbon emissions from shipping has become an increasingly popular topic (Corbett et al. 2009). During the period of 2007 to 2012, on average, carbon emissions from shipping accounted for approximately $3.1 \%$ of annual global carbon emissions (IMO 2015). Shipping has thus far escaped inclusion in the reduction targets of the

*Corresponding author. E-mail: hlyang@dlmu.edu.cn 
Kyoto Protocol, but it is very likely that the era without corresponding regulations is ending and that measures are coming (Guo et al. 2010). In 2016, a new regulation for reducing GreenHouse Gases (GHGs) emissions from shipping, called the "IMO roadmap", was approved, which anticipates that an initial GHGs reduction strategy will be adopted in 2018 (IAA PortNews 2016). A few studies have identified the impacts of carbon emissions policies on the shipping industry. There are two main potential carbon emissions policies available: the cap-and-trade programme and the carbon tax (Aldy, Pizer 2015; Carl, Fedor 2016; Yang et al. 2017). Although the cap-and-trade programme policy is a promising mechanism to reduce $\mathrm{CO}_{2}$ (Miola et al. 2011), an appropriate carbon emissions cap is difficult to establish, because the associated $\mathrm{CO}_{2}$ emissions are uncertain. Under three carbon tax conditions, Wang and $\mathrm{Xu}$ (2015) analysed the optimization decisions for the ship speed of containerships during a voyage. Kim et al. (2012) applied an epsilon-optimal algorithm to optimize a ship's speed when the carbon tax policy was considered. Lee et al. (2013) found that imposing a maritime carbon tax policy on container shipping will not lead to a significant economic impact unless the tax level is high. It is likely that environmental considerations involving containership carbon emissions have farreaching influences on the strategic choices of ship speed and fleet deployment. The existing studies have focused on the effect caused by the cap-and-trade programme policy or by the carbon tax policy, ignoring the condition that both of the carbon emissions policies are imposed on the shipping sector. These two policies have already used in green vendor managed inventory to reduce carbon emissions (Nia et al. 2015). To fill this gap, this paper studies the Ship Speed and Fleet Deployment Problem (hereafter SSFDP) under the cap-and-trade programme policy and the carbon tax policy. These measures will not only impact the total weekly operating costs of the container shipping company, but will also affect carbon emissions reductions.

Compared with the existing studies, the SSFDP under both the cap-and-trade programme and the carbon tax has the following three characteristics:

- Overlap effect. For the cap-and-trade programme policy, it faces the obstacles of allocating reasonable carbon emissions caps (Miola et al. 2011), and the carbon emissions caps may have an indirect effect on the ship speed. For the carbon tax policy, it has a direct impact on the ship speed (Wang, Xu 2015). Compared to employing one policy in the previous studies, the implementation of the cap-and-trade programme and carbon tax policies are likely to have an overlap effect on the SSFDP, which should be analysed more deeply;

- Complex model. Under the condition that the liner routes to be serviced are defined and the container shipping demands are given, the objective function of the ship speed and fleet deployment optimization problem is to minimize the total operating costs of the shipping company (Christiansen et al. 2013).
Carbon emissions are determined by fuel consumption, and fuel consumption is composed of heavy oil consumption and light oil consumption. The calculation methods for these two types of oil consumption are different. Heavy oil consumption is proportional to the third power of ship speed (Yao et al. 2012), while light oil consumption is inversely proportional to the ship's speed (Corbett et al. 2009). Fuel consumption and carbon emissions are the integration of the above two relationships with nonlinear terms and mixed integer terms, which increases the complexity of the model;

- Triple cost trade-off relationship. For the existing studies about the SSFDP, there is one trade-off relationship between the operating costs of containerships and the fuel costs (Wang, Meng 2012; Ronen 2011; Wang et al. 2013a). While for the SSFDP under both the cap-and-trade programme and the carbon tax, there are three trade-off relations. The first relation exists between the operating costs of containerships and fuel costs. The second relation exists between the containerships operating costs and the carbon emissions costs. The third relation exists between the heavy fuel oil costs and the marine diesel oil costs. Therefore, more trade-off factors should be weighed in the optimization process.

In view of the initial GHGs reduction strategy approved by International Maritime Organization (IMO), which will be adopted in 2018 (IAA PortNews 2016), this paper studies the SSFDP under carbon emissions policies. The aim of this study is to provide a scientific method to optimize speeds of ships, as well as number and types of containerships deployed on liner routes for container shipping companies. The remainder of this paper is organized as follows. In Section 1, the problem description is provided. In Section 2, the model formulation is presented. A simulated annealing algorithm is designed to solve the problem in Section 3. To verify the applicability of the model and the effectiveness of the algorithm, numerical experiments are conducted in Section 4. The conclusions are presented in last section.

\section{Problem description}

This paper presents a SSFDP under two carbon emissions policies in container shipping that optimize the ship speed and fleet deployment decision. This tactical planning decision is a major concern for container shipping companies ( $\mathrm{Ng} 2014)$, and it remains unchanged for a period of 3...6 months (Wang, Meng 2012). The length of planning horizon is assumed to be 3 months (i.e. 90 working days), as is the maximum period, over which the cost parameters can be regarded unchanged (Wang, Meng 2012). During the planning horizon, it can be regarded that the container shipping demand is generated evenly, which means on each route there is not much variation in the cargo size of different voyage. Besides, the container shipping demand 
over the planning horizon is independent of frequency and is a priori known (Gelareh, Meng 2010). Therefore, we do not consider the issue of changes in container shipping demand. Containers are usually transported by container shipping companies with fixed sequence of calling ports at a regular service frequency and a published freight rate (Wang, Meng 2017). As the freight rate is often comparatively constant and the container shipping demand is certain, the maximization of the total profit is equal to the minimization of the total operating costs (Xie et al. 2000). Usually, a container shipping company deploys various types of containerships on several routes. In order to deploy the appropriate containerships on these routes, it is crucial for the decision makers to solve three problems: (1) the relationships between ship speed and fuel consumption, (2) container shipping demand on legs, and (3) the composition of total weekly operating costs.

\subsection{Relationships between ship speed and fuel consumption}

A container shipping company operates various routes by set $\{1,2, \ldots, n\}$, and $r \in\{1,2, \ldots, n\}$ represents a route. These routes are regularly served by a set of containership types $\{1,2, \ldots, m\}$, and $v \in\{1,2, \ldots, m\}$ represents a particular containership type.

Fuel consumption costs account for a large proportion of the total operating costs in container shipping, which are closely related to ship speed (Ronen 2011). These costs can be divided into the heavy fuel oil consumed by the main engines and the marine diesel oil consumed by the auxiliary engines (IMO 2015). Therefore, it is necessary to distinguish between these two types of fuel consumption, rather than to just consider heavy fuel oil consumption. For the heavy fuel oil, according to the third power relationship between heavy oil consumption and ship speed (Yao et al. 2012), if $S_{v}^{D}$ [knot] stands for the designed speed of containership type $v$, and $F_{v}^{D}$ [tons] stands for the daily main engine fuel consumption of containership type $v$ on route $r$ with ship speed $s_{v r}$ [knot], the ship speed $s_{v r}$ should be within the economic sailing interval $\left[S_{v}^{\min }, S_{v}^{\max }\right]$. Let binary variable $x_{v r}$ be 1 if containership type $v$ is deployed on route $r$. The heavy fuel consumption of containership type $v$ can be calculated by Equation (1):

$$
F_{v}^{s}=\sum_{r=1}^{n} x_{v r} \cdot\left(\frac{s_{v r}}{S_{v}^{D}}\right)^{3} \cdot F_{v}^{D} .
$$

Let $L_{r}$ [n mile] be the distance of route $r$. The sailing time of every voyage of a containership on route $r$ is inversely proportional to its speed $s_{v r}$, which can be given by Equation (2):

$$
T_{r}^{s}=\frac{L_{r}}{\sum_{v=1}^{m} 24 \cdot s_{v r} \cdot x_{v r}} .
$$

These two kinds of fuel consumption of all containerships equal to the fuel consumption of a voyage for all containerships separately. $F_{v}^{s}$ [tons/day] stands for the fuel consumption rate of the main engine of containership type $v$ with ship speed $s_{v r}$.Therefore, the voyage heavy fuel oil consumption can be given by Equation (3):

$$
\sum_{v=1}^{m} \sum_{r=1}^{n} F_{v}^{s} \cdot T_{r}^{s} \cdot x_{v r}=\frac{\sum_{v=1}^{m} \sum_{r=1}^{n}\left(L_{r} \cdot F_{v}^{D} \cdot s_{v r}^{2} \cdot x_{v r}\right)}{24 \cdot\left(S_{v}^{D}\right)^{3}} .
$$

Therefore, the voyage heavy fuel oil consumption is proportional to the second power of the ship's speed.

The function of the marine diesel oil costs is different from the heavy fuel oil costs. The minimal berthing time $T_{r}^{p}$ [days] stands for the planed port calling time of every voyage on the route. The transit time for a containership type $v$ to traverse route $r$ includes sailing time and planed port calling time, which can be calculated by Equation (4):

$$
T_{v r}=x_{v r} \cdot\left(T_{r}^{p}+T_{r}^{s}\right) \text {. }
$$

The liner frequency is once a week and the number of deployed containerships should be integer values. When the number of containerships is a decimal value, a round-up function $\lceil\cdot]$ is needed. Therefore, the number of containership type $v$ on route $r$ can be calculated by Equation (5):

$$
n_{v r}=\left\lceil\frac{T_{v r}}{7}\right\rceil .
$$

The deployed containerships of each type on all routes are limited to the number of containerships $N_{v}$ owned by the container shipping company.

The transit time equals to the number of containerships multiplied by the weekly frequency. The actual berthing time of every voyage $t_{r}^{a}$ [days] on route $r$ should be adjusted by the sailing time of the voyage, which can be calculated by Equation (6):

$$
t_{r}^{a}=\sum_{v=1}^{m}\left(7 \cdot n_{v r}-T_{r}^{s}\right) \cdot x_{v r} .
$$

$F_{v}^{0}$ [tons] stands for the daily auxiliary engine fuel consumption when berthing. For the voyage marine diesel oil consumption, it can be calculated by Equation (7):

$$
\begin{aligned}
& \sum_{v=1}^{m} \sum_{r=1}^{n} F_{v}^{0} \cdot t_{r}^{a} \cdot x_{v r}= \\
& \sum_{v=1}^{m} \sum_{r=1}^{n} F_{v}^{0} \cdot\left[7 \cdot\left[\frac{\frac{L_{r}}{24 \cdot s_{v r}}+T_{r}^{p}}{7}\right]-T_{r}^{s}\right] \cdot x_{v r} .
\end{aligned}
$$

Therefore, the voyage marine diesel oil consumption is inversely proportional to the ship's speed.

\subsection{Container shipping demand on legs}

A container shipping company provides regular shipping services on different liner routes once a week. The ports of call on every liner route and their sequence have been decided in advance. When serving a route, a container- 
ship starts its voyage at the first port of the route, travels to successive ports and finishes the voyage at its last port. Some port calls on the routes and at the end of the routes always loading and discharging cargo. The same type of containerships should be deployed on the same route with uniform speed (Pantuso et al. 2014). The capacity of the deployed containerships should exceed the container shipping demand between any two consecutive ports, which need to be calculated indirectly through the container shipping demand between any port pairs.

Let $N_{r}$ be the number of calling ports on route $r$, and the sequence of the calling ports can be expressed as follows: $1 \rightarrow 2 \rightarrow \ldots \rightarrow N_{r} \rightarrow 1$. Two consecutive ports on a shipping line $r$ constitute a leg (Meng, Wang 2011). When a containership sails from port $k$ to port $k+1$ (leg $k$ ), the containers carried by the containership will include the ones loaded from the previously visited ports, which may be unloaded at port $k+1$ or at subsequent ports, and those loaded at port $k . D_{r}^{i j}$ [FEUs] denotes the container shipping demands from port $i$ to port $j$ on route $r$, and $Y_{r}^{k}$ [FEUs] denotes the container shipping demand of leg $k$ on route $r$. Equation (8) indicates the container shipping demand of the first leg on route $r$ :

$$
Y_{r}^{1}=\sum_{j=2}^{n_{r}} D_{r}^{1 j}+\sum_{i=3}^{n_{r}} \sum_{j=2}^{i-1} D_{r}^{i j}
$$

The container shipping demand of the subsequent legs on route $r$ can be calculated based on the first leg. The container shipping demand of leg $k$ on route $r$ equals to the shipping demand of leg $k-1$ minus the unloading demand of the containers on port $k$ plus the loading demand of the containers on port $k$. The container shipping demand of the leg $k \in\left\{2, \ldots, N_{r}\right\}$ on route $r$ is given by Equation (9):

$$
Y_{r}^{k}=Y_{r}^{k-1}-\sum_{i=1}^{n_{r}} D_{r}^{i k}+\sum_{j=1}^{n_{r}} D_{r}^{k j}, k \in\left\{2, \ldots, N_{r}\right\} .
$$

\subsection{The composition of total weekly operating costs}

The SSFDP aims at minimising the total weekly operating costs of the container shipping company. It is necessary to note that the total weekly operating costs include operating costs of the deployed containerships, fuel costs, carbon emissions costs and port calling costs.

Let $C_{v}$ [\$/day] be the daily operating costs of each containership of type $v$. The operating costs of the deployed containerships can be calculated by Equation (10):

$$
\sum_{v=1}^{m} \sum_{r=1}^{n} 7 \cdot C_{v} \cdot n_{v r} \cdot x_{v r}
$$

$P_{1}$ [\$/ton] denotes the average price of heavy fuel oil during the planning period. $P_{2}$ [\$/ton] denotes the average price of marine diesel oil during the planning period. These two types of fuel consumption multiplied by their corresponding price equals to the fuel costs separately. Because these fuels conduce to air pollution in the form of sulphur and particulate matter, various international or- ganisations and institutions impose environment standards to limit the emission of green gases (Sys et al. 2016). In 2008 the IMO decided on more stringent requirements for airborne emissions of sulphur dioxide from sea transports in the Sulphur Emission Control Area (SECA) (Vierth et al. 2015). It means that containerships entering the region, which need to adhere to SECA regulation, containerships should only use the more expensive marine gas oil with lower sulphur for both the auxiliary power and the main engine (Schinas, Stefanakos 2012). Let $L_{r 1}$ [n mile] be the distance in sulphur emission control areas on route $r$. Let $T_{r 1}$ [days] be the berthing time in sulphur emission control areas on route $r . P_{3}$ [\$/ton] denotes the average price of marine gas oil during the planning period. Thus, fuel costs can be calculated by Equation (11):

$$
\begin{aligned}
& \sum_{v=1}^{m} \sum_{r=1}^{n}\left(\frac{P_{1} \cdot F_{v}^{s} \cdot\left(L_{r}-L_{r 1}\right)}{24 \cdot s_{v r}}+\right. \\
& \left.\frac{P_{3} \cdot F_{v}^{s} \cdot L_{r 1}}{24 s_{v r}}+P_{2} \cdot F_{v}^{0} \cdot\left(t_{r}^{a}-T_{r 1}\right)+P_{3} \cdot F_{v}^{0} \cdot T_{r 1}\right) \cdot x_{v r} .
\end{aligned}
$$

Carbon emissions are produced by fuel consumption. $A_{1}\left[\mathrm{~g} / \mathrm{g}_{\text {fuel }}\right]$ and $A_{2}\left[\mathrm{~g} / \mathrm{g}_{\text {fuel }}\right]$ denote the carbon emissions factor of the heavy fuel oil and maritime diesel oil, respectively. $A_{3}\left[\mathrm{~g} / \mathrm{g}_{\text {fuel }}\right]$ denotes the carbon emissions factor of the marine gas oil. Therefore, total carbon emissions on all routes can be given by Equation (12):

$$
\begin{aligned}
& \sum_{v=1}^{m} \sum_{r=1}^{n}\left(\frac{A_{1} \cdot F_{v}^{s} \cdot\left(L_{r}-L_{r 1}\right)}{24 \cdot s_{v r}}+\right. \\
& \left.\frac{A_{3} \cdot F_{v}^{s} \cdot L_{r 1}}{24 \cdot s_{v r}}+A_{2} \cdot F_{v}^{0} \cdot\left(t_{r}^{a}-T_{r 1}\right)+A_{3} \cdot F_{v}^{0} \cdot T_{r 1}\right) \cdot x_{v r} .
\end{aligned}
$$

By implementing the carbon tax policy, carbon emissions are transferred to the carbon emissions costs, which can be added into the total weekly operating costs function. $E[\$ /$ ton] denotes carbon tax per ton. Therefore, the carbon emissions costs can be calculated by Equation (13):

$$
\begin{aligned}
& E \cdot \sum_{v=1}^{m} \sum_{r=1}^{n}\left(\frac{A_{1} \cdot F_{v}^{s} \cdot\left(L_{r}-L_{r 1}\right)}{24 \cdot s_{v r}}+\right. \\
& \left.\frac{A_{3} \cdot F_{v}^{s} \cdot L_{r 1}}{24 \cdot s_{v r}}+A_{2} \cdot F_{v}^{0} \cdot\left(t_{r}^{a}-T_{r 1}\right)+A_{3} \cdot F_{v}^{0} \cdot T_{r 1}\right) \cdot x_{v r}
\end{aligned}
$$

Regarding the cap-and-trade programme policy, carbon emissions are controlled at a certain level under carbon emissions cap. If the cap of total carbon emissions on all routes is $U_{e}$ [tons], it can be given by Equation (14):

$$
\begin{aligned}
& \sum_{v=1}^{m} \sum_{r=1}^{n}\left(\frac{A_{1} \cdot F_{v}^{s} \cdot\left(L_{r}-L_{r 1}\right)}{24 \cdot s_{v r}}+\right. \\
& \left.\frac{A_{3} \cdot F_{v}^{s} \cdot L_{r 1}}{24 \cdot s_{v r}}+A_{2} \cdot F_{v}^{0} \cdot\left(t_{r}^{a}-T_{r 1}\right)+A_{3} \cdot F_{v}^{0} \cdot T_{r 1}\right) \times \\
& x_{v r} \leq U_{e} .
\end{aligned}
$$

The port calling costs include the fixed costs and the variable costs. The fixed costs are determined by the location of the port and the capacity. Let $G_{r i}[\$]$ be the fixed 
cost for visiting port $i$ on route $r$. The variable costs are concerned with the type of containerships in the calling ports. Let $O_{r i}$ [ $\left.\$ / \mathrm{FEU}\right]$ be the variable costs for visiting port $i$ on route $r$. Let $B_{v}$ [FEUs] be the container capacity of containership type $v$. Thus, the port calling costs can be calculated by Equation (15):

$$
\sum_{v=1}^{m} \sum_{r=1}^{n} \sum_{i=1}^{N_{r}}\left(G_{r i}+O_{r i} \cdot B_{v}\right) \text {. }
$$

\section{Model formulation}

Based on the assignment of different types of containerships for each route, the optimized ship speed and fleet deployment should be designed, which should minimize the total weekly operating costs of the container shipping company. According to the above analysis, the proposed SSFDP model under the cap-and-trade programme policy and the carbon tax policy can be formulated as follows:

$$
\begin{aligned}
& \min C=\sum_{v=1}^{m} \sum_{r=1}^{n} 7 \cdot C_{v} \cdot n_{v r} \cdot x_{v r}+ \\
& \sum_{v=1}^{m} \sum_{r=1}^{n}\left(\frac{P_{1} \cdot F_{v}^{s} \cdot\left(L_{r}-L_{r 1}\right)}{24 \cdot s_{v r}}+\right. \\
& \left.\frac{P_{3} \cdot F_{v}^{s} \cdot L_{r 1}}{24 \cdot s_{v r}}+P_{2} \cdot F_{v}^{0} \cdot\left(t_{r}^{a}-T_{r 1}\right)+P_{3} \cdot F_{v}^{0} \cdot T_{r 1}\right) \cdot x_{v r}+ \\
& E \cdot \sum_{v=1}^{m} \sum_{r=1}^{n}\left(\frac{A_{1} \cdot F_{v}^{s} \cdot\left(L_{r}-L_{r 1}\right)}{24 \cdot s_{v r}}+\right. \\
& \left.\frac{A_{3} \cdot F_{v}^{s} \cdot L_{r 1}}{24 \cdot s_{v r}}+A_{2} \cdot F_{v}^{0} \cdot\left(t_{r}^{a}-T_{r 1}\right)+A_{3} \cdot F_{v}^{0} \cdot T_{r 1}\right) \cdot x_{v r}+ \\
& \sum_{v=1}^{m} \sum_{r=1}^{n} \sum_{i=1}^{N_{r}}\left(G_{r i}+O_{r i} \cdot B_{v}\right)
\end{aligned}
$$

subject to:

$$
\begin{aligned}
& Y_{r}^{k}<\sum_{v=1}^{m} x_{v r} B_{v}, \forall r \in R, k \in\left\{1,2, \ldots, N_{r}\right\} ; \\
& \sum_{v=1}^{m} \sum_{r=1}^{n}\left(\frac{A_{1} \cdot F_{v}^{s} \cdot\left(L_{r}-L_{r 1}\right)}{24 \cdot s_{v r}}+\right. \\
& \left.\frac{A_{3} \cdot F_{v}^{s} \cdot L_{r 1}}{24 \cdot s_{v r}}+A_{2} \cdot F_{v}^{0} \cdot\left(t_{r}^{a}-T_{r 1}\right)+A_{3} \cdot F_{v}^{0} \cdot T_{r 1}\right) \times \\
& x_{v r} \leq U_{e} ; \\
& T_{r}^{s}=\frac{L_{r}}{\sum_{v=1}^{m} 24 \cdot s_{v r} \cdot x_{v r}}, \forall r \in R ; \\
& T_{v r}=x_{v r} \cdot\left(T_{r}^{p}+T_{r}^{s}\right), \forall v \in V, r \in R ; \\
& n_{v r}=\left[\frac{T_{v r}}{7}\right], \forall v \in V, r \in R ; \\
& t_{r}^{a}=\sum_{v=1}^{m}\left(7 \cdot n_{v r}-T_{r}^{s}\right) \cdot x_{v r}, \forall r \in R ;
\end{aligned}
$$

$$
\begin{aligned}
& \sum_{r=1}^{n} x_{v r} \cdot n_{v r} \leq N_{v}, \forall v \in V ; \\
& \sum_{v=1}^{m} x_{v r}=1, \quad \forall r \in R ; \\
& S_{v}^{\min } \leq \sum_{r=1}^{n} x_{v r} \cdot s_{v r} \leq S_{v}^{\max }, \forall v \in V ; \\
& x_{v r} \in\{0,1\}, \forall v \in V, r \in R ; \\
& n_{v r} \in Z^{+}, \forall v \in V, r \in R .
\end{aligned}
$$

The objective function (16) minimizes the total weekly operating costs. Constraint (17) ensures that the capacity of the containerships deployed on route $r$ satisfy the container shipping demand of each leg. Constraint (18) states the carbon emissions cap of all routes. Constraint (19) states the sailing time of every voyage of containerships on route $r$. Constraint (20) determines the transit time of a containership type $v$ to traverse route $r$. Constraint (21) determines the number of type $v$ containerships on route $r$, which should meet the weekly service requirement. Constraint (22) is the actual port calling time of every voyage on route $r$. Constraint (23) states that the number of deployed containerships of each type should not exceed the number of containerships owned by the container shipping company. Constraint (24) guarantees that every route is deployed with only one type of containership. The range of the ship speed can be ascertained from constraint (25). Then, in constraint (26), the binary variable $x_{v r}$ is the key to determine whether the containership type $v$ is deployed on route $r$. Finally, constraint (27) ensures the number of the deployed type $v$ containership on route $r$ are integers.

\section{Algorithm}

The above model is a non-linear mixed integer programming model with non-liner terms in its objective function (16), which has a quadratic term and a reciprocal term. Moreover, constraints (18)-(22) are all non-liner terms. It is a hard combinatorial optimization problem where the decision variables include continuous variables, integer variables and binary variables. Besides the number of deployed containerships, constraint involves rounding issue. Such a mixed-integer nonlinear programming model is not a very well explored field and there is no commercial software, which allows to solve this kind of problem directly in an efficient way (Teghem et al. 1995). Therefore, an effective algorithm should be chosen to tackle this model. The Simulated Annealing Algorithm (SAA) is a process for solving optimization problems by reducing search space (Kirkpatrick et al. 1983). This algorithm is designed to find a global optimal result faster than other unsophisticated random search methods (Ketabchi, Ataie-Ashtiani 2015; Zhao, Zeng 2006). It works efficiently on a neighbourhood search within solution space, acceptance probability, and inferior solutions to escape from being trapped in a local mini- 
mum energy state (Javadian et al. 2011). Furthermore, the SAA have been proved to be extremely efficient for solving the hard combinatorial optimization problems (Teghem et al. 1995; Jahangiri et al. 2011). Thus, we employ this method to solve the proposed model founded in this paper. The flowchart of the SAA for the SSFDP under carbon emissions policies is described in Figure 1.

The main steps of the SAA are explained as follows.

Step 1: Generating an initial solution. There are $m$ types of containerships; sort these containerships by size from smallest to largest. The initial solution $S_{1}$ has two parts. Part 1 represents the fleet deployment matrix with the number of 1 or 0 with $m \times n$ dimension ( 1 means the deployment of containerships on the route, and 0 means no deployment). Part 2 represents the ship speed matrix with $m \times n$ dimension (the non-zero real number represents the corresponding ship speed on the route). Compare $B_{v}$ (container capacity of containership type $v$ ) with $Y_{r}^{k}$ (the container shipping demand of leg $k$ on route $r$ ). If $Y_{r}^{k}<B_{v}$, then the containerships type $v$ and the latter containerships can be deployed on this route; these containership types are deemed viable containerships in the following text because the same type of containerships should be deployed on the same route. Number 1 only appears once in each column in the fleet deployment matrix. The ship speed matrix columns generate values within the ship speed range at the same places corresponding to the fleet deployment matrix, whereas the others are coded as 0 . Figure 2 shows an initial solution for three types of containerships with three routes. This method can quickly generate the initial solution, which increases the speed of the solutions of the following steps.

Step 2: Creating new solutions. Select any column coded 1 in the fleet deployment matrix for the current solution and then change it from 1 to 0 . Therefore, the values of the corresponding places in the fleet deployment will change to 0 . Additionally, redeploy the viable containerships on this route by changing the position number of this column from 0 to 1 . Furthermore, the values of the corresponding locations in the ship speed matrix can be generated within the ship speed range. Thus, the fleet deployment and ship speed matrices constitute a new solution $S_{2}$.

Step 3: Acceptance criterion of the new solutions. The total weekly operating costs $C(S)$ can be calculated by Equation (16). When the total carbon emissions exceed their cap $U_{e}$, this can be expressed by Equation (28):

$$
\begin{aligned}
& \sum_{v=1}^{m} \sum_{r=1}^{n}\left(\frac{A_{1} \cdot F_{v}^{s} \cdot\left(L_{r}-L_{r 1}\right)}{24 \cdot s_{v r}}+\right. \\
& \left.\frac{A_{3} \cdot F_{v}^{s} \cdot L_{r 1}}{24 \cdot s_{v r}}+A_{2} \cdot F_{v}^{0} \cdot\left(t_{r}^{a}-T_{r 1}\right)+A_{3} \cdot F_{v}^{0} \cdot T_{r 1}\right) \times \\
& x_{v r}>U_{e} .
\end{aligned}
$$

Then, penalty costs $H_{0}$ should be added to the above costs. Thus, the total weekly operating costs function can be given by Equation (29):

$$
Z(S)=C(S)+H_{0}
$$

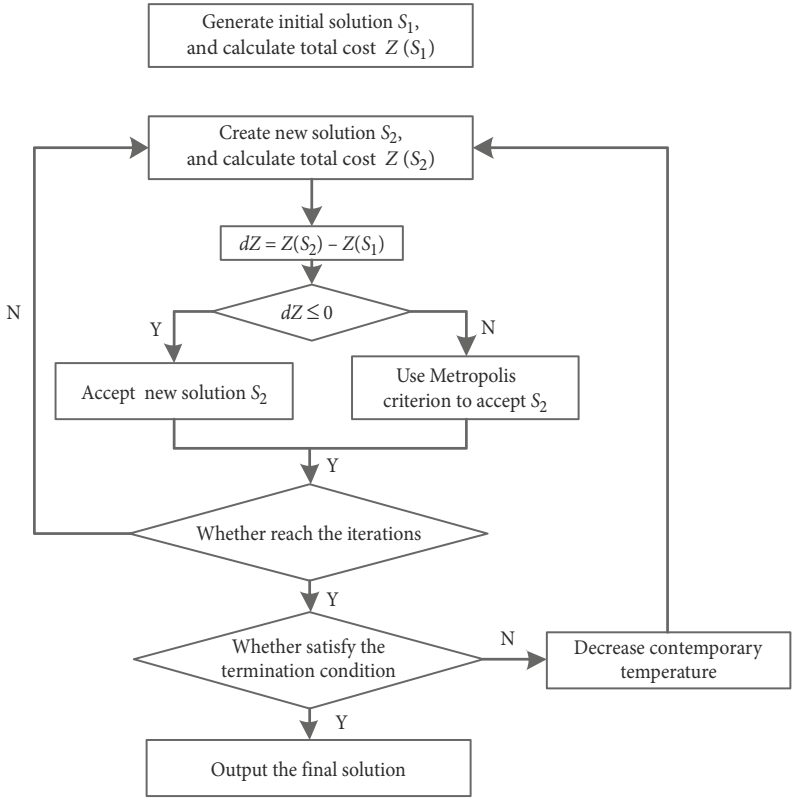

Figure 1. Flow chart of simulated annealing algorithm

$$
\begin{aligned}
& \begin{array}{lll}
R 1 & R 2 & R 3
\end{array} \\
& \text { Ship type } 1\left[\begin{array}{lll}
0 & 0 & 1
\end{array}\right] \\
& \text { Ship type 2 } 1100 \\
& \text { Ship type } 3\left[\begin{array}{lll}
0 & 1 & 0
\end{array}\right] \\
& \text { Fleet deployment matrix }
\end{aligned}
$$

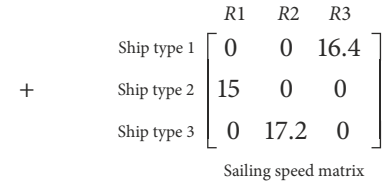

$$
\begin{aligned}
& \begin{array}{lllllllll}
0 & 1 & 1 & 0 & 0 & 0 & 1 & 0 \\
\hline
\end{array} \\
& \begin{array}{llllllllll}
0 & 0 & 16.4 & 15 & 0 & 0 & 0 & 17 & .2 & 0
\end{array}
\end{aligned}
$$

Figure 2. The initial solution

Different solutions obtain a different number of containership type $v$ on route $r$. When the number of containership type $v$ surpasses the number of shipping company's owned containerships, this can be expressed by Equation (30):

$$
\sum_{r=1}^{n} x_{v r} \cdot n_{v r} \geq N_{v} .
$$

The excessive containership's operating costs will be added into the penalty costs. The penalty cost of each containership is $M_{0}$. Thus, the total weekly operating costs can be calculated by Equation (31):

$$
Z(S)=C(S)+M_{0} \cdot\left(\sum_{r=1}^{n} x_{v r} \cdot n_{v r}-N_{v}\right) .
$$

Therefore, the total weekly operating costs of the initial solution is $Z\left(S_{1}\right)$, and the new solution is $Z\left(S_{2}\right)$. The costs difference are $d Z=Z\left(S_{2}\right)-Z\left(S_{1}\right)$. If $d Z<0$, the new solution will be accepted with the probability of 1 ; otherwise, it will be accepted with the probability of $\exp \left(-\frac{d Z}{T}\right)$.

Step 4: Algorithm termination judgement. The algorithm annealing process is controlled by the contemporary temperature. The original temperature is $T_{0}$, and the terminal temperature is $T_{\text {end }}$. We conduct an iteration $L$ times at each temperature and decrease the temperature 
by the cooling rate of $q$. In other words, the new temperature is $T=q \cdot T$, and the optimization solution is selected based on the acceptance criterion of the new solutions. The algorithm stops if the final temperature $T$ is smaller than the terminal temperature. The last step is to generate the final solution.

\section{Numerical experiments}

In this section, four liner routes from Asia to the west coast of the United States were selected to verify the applicability and effectiveness of the established model and the algorithm. Data were selected from the benchmark suite (Brouer et al. 2014). Table 1 illustrates the parameters of the four routes, including the route distance, port calling sequence and the minimal berthing time. Table 2 illustrates the parameters of the containerships, such as the capacity of containerships, the operating cost of each type of containership, the containerships owned by the shipping company, etc.

There are 126 pairs of demand for the four routes in the benchmark suite. We only show one examples of the container shipping demand between port pairs. For example, the container shipping demand from the port of Los Angeles to Shanghai is 420 FEUs. The fixed costs of the calling port are determined by the geographical location and the capacity, and the variable costs are related to the capacity of the containerships visiting the port. For example, the fixed costs of the Los Angeles port are 6876 \$/visit, and the variable costs are $2 \$ / F E U$.

We do not consider the SECA regulation in this numerical experiments, so $L_{r 1}=0, T_{r 1}=0, r \in\{1,2,3,4\}$. According to the Third IMO Greenhouse Gas Study 2014 (IMO 2015) and current market situations. The other parameters used in the model are given as follows: $A_{1}=3.114 \mathrm{~g} / \mathrm{g}_{\text {fuel }}$, $A_{2}=3.206 \mathrm{~g} / \mathrm{g}_{\text {fuel }}, P_{1}=300 \$ /$ ton and $P_{2}=600 \$ /$ ton. The carbon tax is $E=10 \$ /$ ton and the carbon emissions cap is $U_{e}=4000$ tons.

Computer calculations of the SAA were performed with different parameters. To find better parameters, the robustness of the proposed SAA was measured for ten cases, shown in Table 3. $\Delta$ is the deviation ratio between the objective value and the minimum objective value.

The SAA parameters were selected based on the results in Table 3: the original temperature is set to be $T_{0}=2000$, the terminal temperature is $T_{\text {end }}=10^{-4}$, iteration per temperature is $L=500$, and temperature cooling rate is $q=0.98$. The penalty costs should be set to a large value: $M_{0}=10^{9} \$, H_{0}=10^{9} \$$. The model described in Section 3 and the SAA were implemented with the Windows 7 Operating system. All numerical experiments were performed with a personal computer with an Intel Core i7 processor

Table 1. Parameters of routes

\begin{tabular}{|c|c|l|l|}
\hline$r$ & $L_{r}[\mathrm{n}$ mile] & \multicolumn{1}{|c|}{$1 \rightarrow 2 \rightarrow \ldots \rightarrow N_{r} \rightarrow 1$} & $T_{r}^{p}[$ days $]$ \\
\hline 1 & 13224 & Dalian $\rightarrow$ Pusan $\rightarrow$ Tokyo $\rightarrow$ Vancouver $\rightarrow$ Seattle $\rightarrow$ Los Angeles $\rightarrow$ Yokohama $\rightarrow$ Shanghai & 2.7 \\
\hline 2 & 13144 & Hong Kong $\rightarrow$ Yantian $\rightarrow$ Kaohsiung $\rightarrow$ Los Angeles $\rightarrow$ Oakland $\rightarrow$ Pusan $\rightarrow$ Xiamen & 3.2 \\
\hline 3 & 13140 & Yantian $\rightarrow$ Fuzhou $\rightarrow$ Yokohama $\rightarrow$ Oakland $\rightarrow$ Los Angeles $\rightarrow$ Tokyo $\rightarrow$ Kaohsiung & 2.3 \\
\hline 4 & 15849 & Singapore $\rightarrow$ Ho Chi Minh $\rightarrow$ HongKong $\rightarrow$ Shanghai $\rightarrow$ Kobe $\rightarrow$ Oakland $\rightarrow$ Seattle $\rightarrow$ Xiamen & 2.0 \\
\hline
\end{tabular}

Table 2. Parameters of fleets

\begin{tabular}{|c|c|c|c|c|c|c|c|c|}
\hline$v, v \in V$ & $B_{v}[$ FEUs $]$ & $C_{v}[\$ /$ day $]$ & $N_{v}$ & $S_{v}^{D}[\mathrm{knot}]$ & $S_{v}^{\min }[\mathrm{knot}]$ & $S_{v}^{\max }[\mathrm{knot}]$ & $F_{v}^{0}[$ tons $]$ & $F_{v}^{D}[\mathrm{tons}]$ \\
\hline 1 & 7500 & 55000 & 15 & 17.0 & 12 & 22 & 10.0 & 126.9 \\
\hline 2 & 4200 & 35000 & 14 & 16.5 & 12 & 23 & 7.4 & 82.2 \\
\hline
\end{tabular}

Table 3. Measuring robustness of the proposed SAA

\begin{tabular}{|c|c|c|c|c|c|c|}
\hline Number & $\begin{array}{c}\text { Initial } \\
\text { temperature }\end{array}$ & $\begin{array}{c}\text { Temperature } \\
\text { cooling rate }\end{array}$ & $\begin{array}{c}\text { Final } \\
\text { temperature }\end{array}$ & $\begin{array}{c}\text { Number of } \\
\text { iterations }\end{array}$ & $\begin{array}{c}\text { Objective value } \\
{[\text { million } \$]}\end{array}$ & $\Delta$ [\%] \\
\hline 1 & 2000 & 0.99 & 0.0001 & 400 & 11.770 & 0.07 \\
\hline 2 & 1000 & 0.99 & 0.0001 & 300 & 11.765 & 0.03 \\
\hline 3 & 2000 & 0.98 & 0.0001 & 500 & 11.762 & 0.00 \\
\hline 4 & 1000 & 0.98 & 0.0001 & 300 & 11.764 & 0.02 \\
\hline 5 & 1000 & 0.98 & 0.001 & 500 & 11.766 & 0.03 \\
\hline 6 & 1000 & 0.97 & 0.001 & 300 & 11.767 & 0.04 \\
\hline 7 & 2000 & 0.97 & 0.001 & 500 & 11.769 & 0.06 \\
\hline 8 & 2000 & 0.96 & 0.0001 & 400 & 11.772 & 0.09 \\
\hline 9 & 1000 & 0.96 & 0.0001 & 300 & 11.775 & 0.11 \\
\hline 10 & 1000 & 0.96 & 0.001 & 500 & 11.778 & 0.14 \\
\hline
\end{tabular}


having 3.6 GHz CPU, 8 GB RAM. The optimization results obtained by SAA indicate Route 1 and Route 4 are deployed with 4200 FEUs containerships and Route 2 and Route 3 are deployed with 7500 FEUs containerships. The ship speeds of containerships on four liner routes are 14.1, $14.2,13.8$ and 14.1 knots, respectively. The corresponding numbers of containerships are $6,6,6$ and 7. Total weekly operating costs are 11.762 million $\$$ and total carbon emissions are 31298 tons.

In order to further validate the effectiveness and efficiency of SAA, we refer to the Discretization Method (hereafter DM) (Wang et al. 2013a, 2013b; Gelareh, Meng 2010; Yao et al. 2012) used in recent researches on solving ship speed optimization problems. The solution obtained by DM can be regarded as an approximate exact solution. This method takes the reciprocal of ship speed as a new decision variable and then discretize the new variable (Wang et al. 2013a, 2013b). Therefore, the nonlinear programming model is transformed into a linear programming model, which can be solved by CPLEX. The detailed solving process of DM is given in the Appendix.

After traversing all the values of $x_{v r}$, the optimization results of SSFDP obtained by CPLEX are shown in Table 4 .

Table 4 shows that the optimization results obtained by the DM are consistent with the results obtained by the SAA. It can be seen that the optimization effects of these two methods are the same. Since the DM is a method that generates approximate exact solution, it indirectly indicates that the SAA is effective.

Table 4. The optimization results of SSFDP

\begin{tabular}{|c|c|c|c|c|}
\hline Parameter & 1 & 2 & 3 & 4 \\
\hline$s_{1 r}$ & & 14.2 & 13.8 & \\
\hline$s_{2 r}$ & 14.1 & & & 14.1 \\
\hline$n_{1 r}$ & & 6 & 6 & \\
\hline$n_{2 r}$ & 6 & & & 7 \\
\hline $\begin{array}{l}\text { Total weekly operating costs } \\
\text { [million \$] }\end{array}$ & \multicolumn{4}{|c|}{11.762} \\
\hline Carbon emissions [tons] & \multicolumn{4}{|c|}{31298} \\
\hline
\end{tabular}

However, using the DM on the proposed model needs a relatively long solving time. That is because the nonlinear model has to be transformed to an integer linear programming model in advance. This transformation process adds a large number of integer variables, which poses considerable computational difficulties. Furthermore, when there is a large number of liner routes and containership types, the model transformation should consider different combinations of containership types and liner routes. The DM needs a lot of human-computer interaction. Therefore, the DM is not easy to apply in practice. Comparing with the $\mathrm{DM}$, the SAA is relatively simpler and faster. It illustrates widely that the SAA is efficient in solving the proposed model in this paper.

The following sections analysed the optimization results from three perspectives: under the consideration of either the cap-and-trade programme policy or the carbon tax policy and with both of the policies.

\subsection{Results analysis under different carbon emissions caps}

To study the impact of the carbon emissions caps, we ignore the carbon $\operatorname{tax}(E=0)$. When the total weekly operating costs reaches the lowest value, carbon emissions are $U=31298$ tons. For the SSDFP model, containerships sailing at the lowest speed would achieve the lowest carbon emissions, or conversely. Therefore, there is a minimum value of $U_{e}^{\min }=23245$ tons and a maximum value of $U_{e}^{\max }=80467$ tons of carbon emissions on all routes. Take a special condition as an example, there is no carbon emissions cap on total carbon emissions, so $U_{e}=\infty$. Therefore, the carbon emissions caps are divided into four intervals. Table 5 shows the SSFDP optimization results under different carbon emissions intervals.

It is obvious that the smaller the carbon emissions cap is, the smaller the range of the feasible solutions. Table 5 shows that for the first case, there is no viable solution if the carbon emissions cap is less than 23245 tons, because carbon emissions cannot be less than its minimum value. For the second case, when the carbon emissions cap is set between 23245 and 31298 tons, the SSFDP optimization results depend on the carbon emissions cap.

Table 5. SSFDP results under different carbon emissions intervals

\begin{tabular}{|c|c|c|c|c|c|c|c|c|c|c|c|c|c|c|c|c|}
\hline & \multicolumn{4}{|c|}{$U_{e} \in[0,23245)$} & \multicolumn{4}{|c|}{$U_{e} \in[23245,31298)$} & \multicolumn{4}{|c|}{$U_{e} \in[31298,80467)$} & \multicolumn{4}{|c|}{$U_{e} \in[80467,+\infty)$} \\
\hline & \multicolumn{4}{|c|}{ Route number } & \multicolumn{4}{|c|}{ Route number } & \multicolumn{4}{|c|}{ Route number } & \multicolumn{4}{|c|}{ Route number } \\
\hline & 1 & 2 & 3 & 4 & 1 & 2 & 3 & 4 & 1 & 2 & 3 & 4 & 1 & 2 & 3 & 4 \\
\hline$s_{1 r}$ & \multirow{4}{*}{\multicolumn{4}{|c|}{ no solution }} & \multirow{4}{*}{\multicolumn{4}{|c|}{ results depend on $U_{e}$}} & & 14.2 & 13.8 & & & 14.2 & 13.8 & \\
\hline$s_{2 r}$ & & & & & & & & & 14.1 & & & 14.1 & 14.1 & & & 14.1 \\
\hline$n_{1 r}$ & & & & & & & & & & 7 & 6 & & & 7 & 6 & \\
\hline$n_{2 r}$ & & & & & & & & & 6 & & & 7 & 6 & & & 7 \\
\hline $\begin{array}{l}\text { Total weekly operating } \\
\text { costs [million \$] }\end{array}$ & & & & & \multicolumn{4}{|c|}{$>11.449$} & \multicolumn{4}{|c|}{11.449} & \multicolumn{4}{|c|}{11.449} \\
\hline $\begin{array}{l}\text { Carbon emissions } \\
\text { [tons] }\end{array}$ & & & & & \multicolumn{4}{|c|}{ depend on $U_{e}$} & \multicolumn{4}{|c|}{31298} & \multicolumn{4}{|c|}{31298} \\
\hline
\end{tabular}


It is certain that the higher the carbon cap is, the lower the total weekly operating costs. If the carbon emissions cap is close to the lower limit of this interval, containerships sail at a low speed close to its minimum speed with more containerships. Only in this case does the container shipping company need to adjust its ship speed and fleet deployment decision based on the carbon emissions caps. The third case obtains the minimum total weekly operating costs of 11.449 million \$, and the carbon emissions are 31298 tons. In addition, the number of containerships decreases as the ship speed increases. The results of the last case it the same with the third one. Comparing the second case with the last two cases, carbon emissions could be better controlled, but the total weekly operating costs will increase. The last two cases have the same optimization results; thus, the carbon emissions cap has no impact on controlling the carbon emissions if the cap value is too large. Consequently, once the carbon emissions cap is set at an unreasonable level, a cap-and-trade policy will not restrict carbon emissions. In other words, container shipping companies could optimize the ship speed and fleet deployment strategy only on the basis of minimising the total weekly operating costs without regarding the carbon emission cap.

\subsection{Results analysis under different carbon taxes}

When we study the impact of different carbon taxes, the carbon emissions cap is also ignored in this condition $\left(U_{e}=\infty\right)$. The carbon taxes were selected from 0 to $40 \$$ /ton at $10 \$$ /ton interval. Table 6 shows the SSFDP optimization results under different carbon taxes.

Table 6 shows that the capacity of containerships are 4200 FEUs on Route 1 and Route 4, and the capacity of containerships are 7500 FEUs on Route 2 and Route 3 . As carbon taxes increases, the liner ship speed has a declining trend while the number of deployed containerships increases. The higher the carbon taxes are, the closer the ship's speed is to its minimum speed. Obviously, the total weekly operating costs increase from 11.449 million dollars to 12.866 million dollars, but the rate of growth is gradually reduced. Carbon emissions are relatively large with no carbon tax imposed. When carbon tax is $10 \$ /$ ton, ship speed and the number of deployed contain- erships remain unchanged. Therefore, if the carbon tax is set relatively low, there is no impact on reducing carbon emissions. Ship speed and fleet deployment decision has not changed, while total weekly operating costs for container shipping companies has increased. When carbon taxes increase to $20 \$ /$ ton and $30 \$ /$ ton, carbon emissions decrease to 27797 tons and 23245 tons, respectively. Thus, the carbon tax policy will lead to a moderate reduction of carbon emissions and a growth of total weekly operating costs. In conclusion, with the increase of carbon taxes, carbon emissions will show a ladder form of declining trend instead of a continuous one. Considering the carbon tax policy, the target-oriented goal is to minimize the total weekly operating costs, so the amount of carbon emissions cannot be effectively control.

\subsection{Results analysis under different carbon emissions caps and carbon taxes}

In this section, sensitivity analysis was performed to explore the impact of changes on the ship speed and fleet deployment when both the cap-and-trade programme policy and the carbon tax policy are imposed. Once the ship speeds on each route are determined, the number of deployed containerships is easy to obtain. The four routes with different ship speed are shown by three-dimensional graphics in Figure 3.

According to Figure 3, Route 1 and Route 4 have similar graphic trends, because these two routes have the same type of containerships, and so do Route 2 and Route 3. Therefore, the impact of the two policies on the same type of containership is similar. In addition, reducing carbon emissions caps and increasing carbon taxes can reduce the ship speeds on Route 1 and Route 4. For Route 2 and Route 3, reducing carbon emissions caps can reduce ship speeds, while increasing the carbon tax has little effect on ship speed changes. This result is due to the deployment containerships on Route 2 and Route 3 being the larger ones, with higher operating costs, and reducing speed may increase the number of containerships, resulting in a sharp increase in the total weekly operating costs. The optimization results not only reduce the total weekly operating costs but also reduce carbon emissions, which makes the overlap effect of the two policies more obvious.

Table 6. SSFDP optimization results under different carbon taxes

\begin{tabular}{|c|c|c|c|c|c|c|c|c|c|c|c|c|c|c|c|c|c|c|c|c|}
\hline & \multicolumn{4}{|c|}{$E=0 \$ /$ ton } & \multicolumn{4}{|c|}{$E=10 \$ /$ ton } & \multicolumn{4}{|c|}{$E=20 \$ /$ ton } & \multicolumn{4}{|c|}{$E=30 \$ /$ ton } & \multicolumn{4}{|c|}{$E=40 \$ /$ ton } \\
\hline & \multicolumn{4}{|c|}{ Route number } & \multicolumn{4}{|c|}{ Route number } & \multicolumn{4}{|c|}{ Route number } & \multicolumn{4}{|c|}{ Route number } & \multicolumn{4}{|c|}{ Route number } \\
\hline & 1 & 2 & 3 & 4 & 1 & 2 & 3 & 4 & 1 & 2 & 3 & 4 & 1 & 2 & 3 & 4 & 1 & 2 & 3 & 4 \\
\hline$s_{1 r}$ & & 14.2 & 13.8 & & & 14.2 & 13.8 & & & 14.2 & 13.8 & & & 12.0 & 12.0 & & & 12.0 & 12.0 & \\
\hline$s_{2 r}$ & 14.1 & & & 14.1 & 14.1 & & & 14.1 & 12.0 & & & 12.3 & 12.0 & & & 12.3 & 12.0 & & & 12.3 \\
\hline$n_{1 r}$ & & 6 & 6 & & & 6 & 6 & & & 6 & 6 & & & 7 & 7 & & & 7 & 7 & \\
\hline$n_{2 r}$ & 6 & & & 7 & 6 & & & 7 & 7 & & & 8 & 7 & & & 8 & 7 & & & 8 \\
\hline $\begin{array}{l}\text { Total weekly operating } \\
\text { costs [million \$] }\end{array}$ & \multicolumn{4}{|c|}{11.449} & \multicolumn{4}{|c|}{11.762} & \multicolumn{4}{|c|}{12.158} & \multicolumn{4}{|c|}{12.634} & \multicolumn{4}{|c|}{12.866} \\
\hline Carbon emissions [tons] & \multicolumn{4}{|c|}{31298} & \multicolumn{4}{|c|}{31298} & \multicolumn{4}{|c|}{27797} & \multicolumn{4}{|c|}{23245} & \multicolumn{4}{|c|}{23245} \\
\hline
\end{tabular}



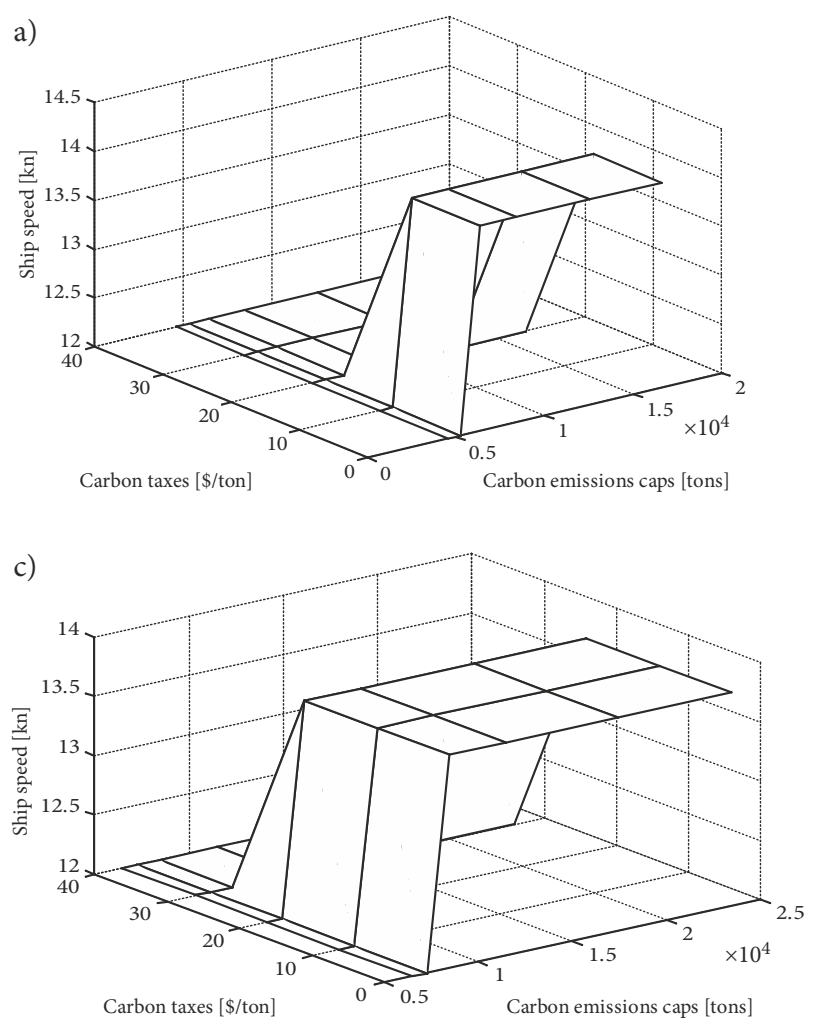

b)

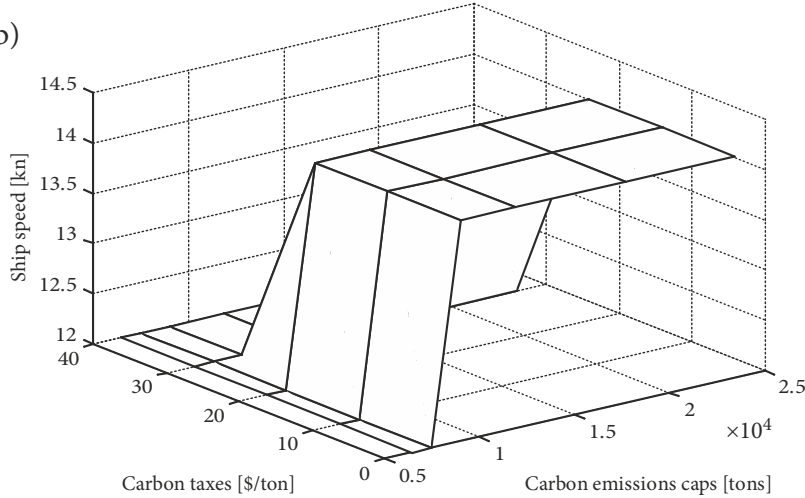

d)

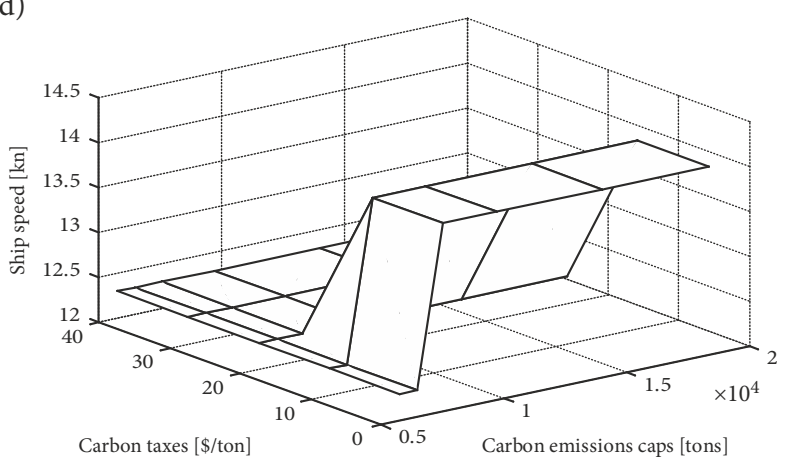

Figure 3. Changes in ship speeds under different carbon taxes and the carbon emissions caps

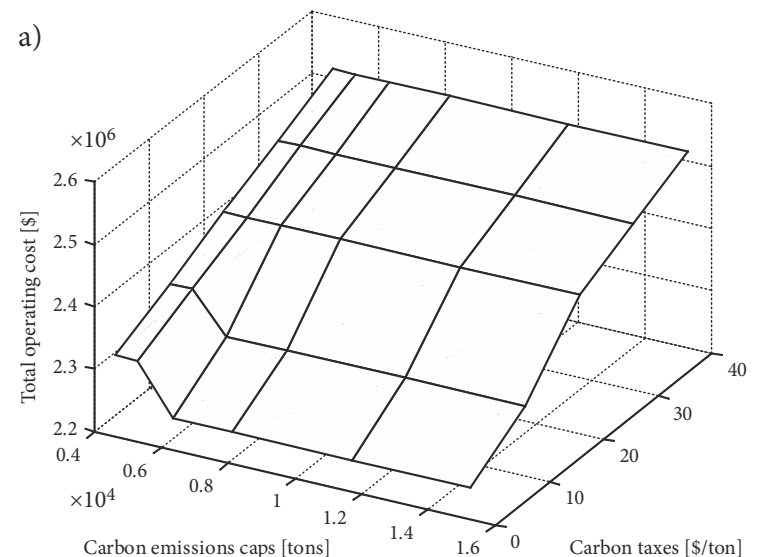

c)

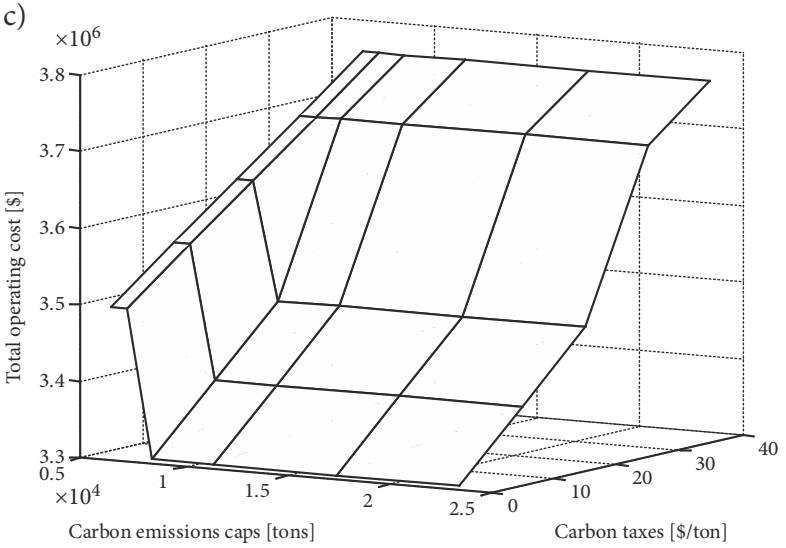

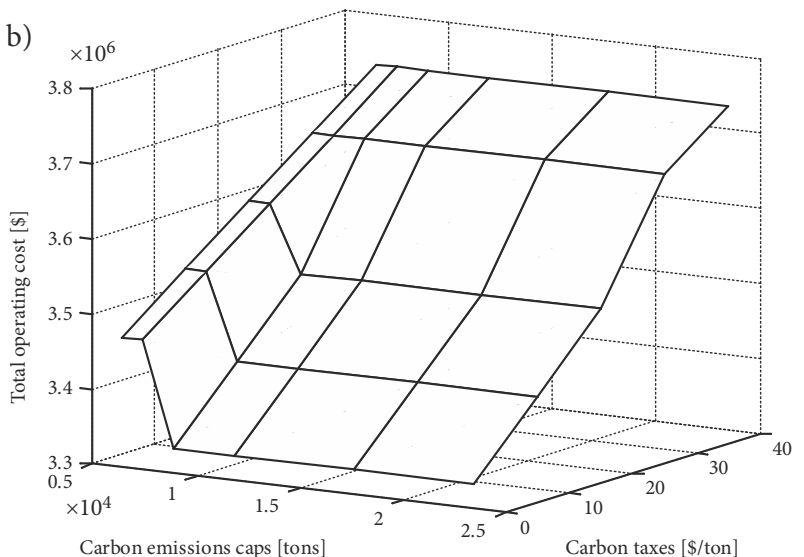

d)

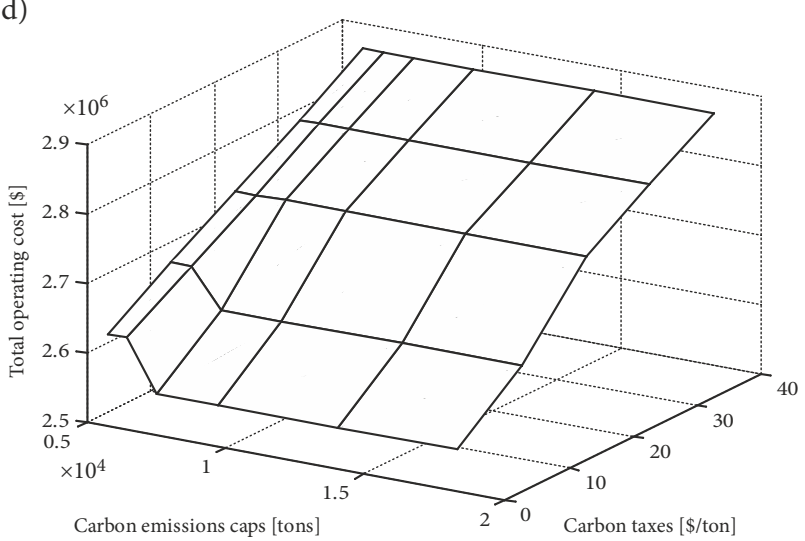

Figure 4. Changes in total weekly operating costs under different carbon emissions caps and different carbon taxes 
In addition, based on the sensitivity analysis, the relationship between total weekly operating costs increased under the different carbon emission caps and different carbon taxes on the four routes, as shown in Figure 4.

Figure 4 shows that with the increase of carbon taxes and the decrease of carbon emissions caps, there is a significant growth in the total weekly operating costs. There is no doubt that increasing carbon taxes and decreasing the carbon emissions caps will lead to a dramatic increase in the carbon emissions costs than only one policy, which is the main factor contributing to the increase in the total weekly operating costs. Meanwhile, as mentioned, the increasing carbon taxes and the decreasing carbon emissions caps will induce a sharp ship speed reduction. However, if the carbon taxes are higher or the carbon emissions caps are lower, the result will not necessarily be better. Because each containership has its own minimum ship speed, when the ship speed is close to its minimum speed, carbon emissions policies do not achieve the effect of reducing carbon emissions.

Maintaining the original ship speed and the number of deployed containerships does not achieve the minimization of the total weekly operating costs under carbon emissions policies. With the development of a low-carbon economy, the container shipping company should not only emphasize operating costs minimization, but also take the related environmental issues into consideration. Therefore, the optimization results of the SSFDP should be adjusted accordingly once the GHGs reduction strategy approved by IMO is adopted. This paper also provided a scientific basis for container shipping companies to implement a ship speed and fleet deployment optimization strategy under carbon emissions policies.

\section{Conclusions}

This paper studied the optimization of ship speed and fleet deployment under two carbon emissions policies, the capand-trade programme and the carbon tax. A non-linear mixed integer programming model was formulated. In view of its convex and non-linear properties, a simulated annealing algorithm was designed to solve the problem. Numerical experiments have been carried out to verify the applicability and effectiveness of the proposed model and the algorithm. The computational results showed that the increasing of carbon taxes and the decreasing of carbon emissions caps will induce a sharp ship speed reduction and an increment of the containership number. Meanwhile, it will lead to a significant growth in the total weekly operating costs and a dramatic decrease in the carbon emissions. To achieve the goal of reducing carbon emissions, the implementation of the two carbon emissions policies can better deal with the ship speed optimization and FDP.

The contributions of this paper are three-fold. First, this paper takes the initiative to study the effect of imposing the cap-and-trade programme policy and the carbon tax policy simultaneously on the SSFDP, which is likely to match the practical development trend of the shipping industry. Second, this study calculates the heavy fuel oil consumption and the marine diesel oil consumption separately. Therefore, the fuel consumption results are more accurate. Third, managerial insights from the numerical experiments are obtained, providing significant guidelines for container shipping companies.

Future research directions are as follows: First, average fuel prices in this paper are regarded as constant in the planning period. With two carbon emission policies, changes in average fuel prices may also affect the optimization results of the ship speed and fleet deployment. Since the average fuel price may be different during different planning period, it should be re-valued in the next planning period. Second, the freight rate fluctuation is not considered in our model. In this paper, the freight rate between any two ports is regarded stable during the planning period. But it is possible that customers seek fast delivery and are willing to pay higher prices for saving time. Then total profit will be affected. In such a case, container shipping companies should regard the maximization of total profit as an objective function rather than the minimization of total operating costs. These two points can be further studied.

\section{Funding}

This work was supported by the National Natural Science Foundation of China [Grant numbers 71372088, 71202108].

\section{Contribution}

The contributions of this paper are three-fold. First, this paper takes the initiative to study the effect of imposing the cap-and-trade programme policy and the carbon tax policy simultaneously on the SSFDP, which is likely to match the practical development trend of the shipping industry. Second, this study calculates the heavy fuel oil consumption and the marine diesel oil consumption separately. Therefore, the fuel consumption results are more accurate. Third, managerial insights from the numerical experiments are obtained, providing significant guidelines for container shipping companies.

\section{Disclosure statement}

No potential conflict of interest was reported by the authors.

\section{References}

Aldy, J. E.; Pizer, W. A. 2015. The competitiveness impacts of climate change mitigation policies, Journal of the Association of Environmental and Resource Economists 2(4): 565-595. https://doi.org/10.1086/683305

Brouer, B. D.; Alvarez, J. F.; Plum, C. E. M.; Pisinger, D.; Sigurd, M. M. 2014. A base integer programming model and benchmark suite for liner-shipping network design, Transportation Science 48(2): 281-312.

https://doi.org/10.1287/trsc.2013.0471 
Carl, J.; Fedor, D. 2016. Tracking global carbon revenues: a survey of carbon taxes versus cap-and-trade in the real world, Energy Policy 96: 50-77. https://doi.org/10.1016/j.enpol.2016.05.023

Christiansen, M.; Fagerholt, K.; Nygreen, B.; Ronen, D. 2013. Ship routing and scheduling in the new millennium, European Journal of Operational Research 228(3): 467-483. https://doi.org/10.1016/j.ejor.2012.12.002

Corbett, J. J.; Wang, H.; Winebrake, J. J. 2009. The effectiveness and costs of speed reductions on emissions from international shipping, Transportation Research Part D: Transport and Environment 14(8): 593-598.

https://doi.org/10.1016/j.trd.2009.08.005

Gelareh, S.; Meng, Q. 2010. A novel modeling approach for the fleet deployment problem within a short-term planning horizon, Transportation Research Part E: Logistics and Transportation Review 46(1): 76-89.

https://doi.org/10.1016/j.tre.2009.06.004

Guo, J.; Zou, L.-L.; Wei, Y.-M. 2010. Impact of inter-sectoral trade on national and global $\mathrm{CO}_{2}$ emissions: an empirical analysis of China and US, Energy Policy 38(3): 1389-1397. https://doi.org/10.1016/j.enpol.2009.11.020

IAA PortNews. 2016. MEPC 70 Approves IMO 'Roadmap' for GHG Reduction Strategy. Information \& Analytical Agency PortNews (IAA PortNews). Available from Internet: http://en.portnews.ru/news/229015

IMO. 2015. Third IMO Greenhouse Gas Study 2014. International Maritime Organization (IMO), London, UK. 327 p. Available from Internet: http://www.imo.org/en/OurWork/ Environment/PollutionPrevention/AirPollution/Documents/ Third\%20Greenhouse\%20Gas\%20Study/GHG3\%20Executive\%20Summary\%20and\%20Report.pdf

Jahangiri, A.; Afandizadeh, S.; Kalantari, N. 2011. The optimization of traffic signal timing for emergency evacuation using the simulated annealing algorithm, Transport 26(2): 133-140. https://doi.org/10.3846/16484142.2011.584959

Jaramillo, D. I.; Perakis, A N. 1991. Fleet deployment optimization for liner shipping. Part 2. Implementation and results, Maritime Policy \& Management: the Flagship Journal of International Shipping and Port Research 18(4): 235-262. https://doi.org/10.1080/03088839100000028

Javadian, N.; Sayarshad, H. R.; Najafi, S. 2011. Using simulated annealing for determination of the capacity of yard stations in a railway industry, Applied Soft Computing 11(2): 1899-1907. https://doi.org/10.1016/j.asoc.2010.06.006

Ketabchi, H.; Ataie-Ashtiani, B. 2015. Evolutionary algorithms for the optimal management of coastal groundwater: A comparative study toward future challenges, Journal of Hydrology 520: 193-213. https://doi.org/10.1016/j.jhydrol.2014.11.043

Kim, H.-J.; Chang, Y.-T.; Kim, K.-T.; Kim, H.-J. 2012. An epsilon-optimal algorithm considering greenhouse gas emissions for the management of a ship's bunker fuel, Transportation Research Part D: Transport and Environment 17(2): 97-103. https://doi.org/10.1016/j.trd.2011.10.001

Kirkpatrick, S.; Gelatt, C. D.; Vecchi, M. P. 1983. Optimization by simulated annealing, Science 220(4598): 671-680. https://doi.org/10.1126/science.220.4598.671

Lee, T.-C.; Chang, Y.-T.; Lee, P. T. W. 2013. Economy-wide impact analysis of a carbon tax on international container shipping, Transportation Research Part A: Policy and Practice 58: 87-102. https://doi.org/10.1016/j.tra.2013.10.002

Meng, Q.; Wang, T. 2010. A chance constrained programming model for short-term liner ship fleet planning problems, Maritime Policy \& Management: the Flagship Journal of International Shipping and Port Research 37(4): 329-346. https://doi.org/10.1080/03088839.2010.486635
Meng, Q.; Wang, S. 2011. Liner shipping service network design with empty container repositioning, Transportation Research Part E: Logistics and Transportation Review 47(5): 695-708. https://doi.org/10.1016/j.tre.2011.02.004

Miola, A.; Marra, M.; Ciuffo, B. 2011. Designing a climate change policy for the international maritime transport sector: Market-based measures and technological options for global and regional policy actions, Energy Policy 39(9): 5490-5498. https://doi.org/10.1016/j.enpol.2011.05.013

$\mathrm{Ng}$, M. W. 2015. Container vessel fleet deployment for liner shipping with stochastic dependencies in shipping demand, Transportation Research Part B: Methodological 74: 79-87. https://doi.org/10.1016/j.trb.2015.01.004

Ng, M. W. 2014. Distribution-free vessel deployment for liner shipping, European Journal of Operational Research 238(3): 858-862. https://doi.org/10.1016/j.ejor.2014.04.019

Nia, A. R.; Hemmati Far, M.; Niaki, S. T. A. 2015. A hybrid genetic and imperialist competitive algorithm for green vendor managed inventory of multi-item multi-constraint EOQ model under shortage, Applied Soft Computing 30: 353-364. https://doi.org/10.1016/j.asoc.2015.02.004

Notteboom, T. E.; Vernimmen, B. 2009. The effect of high fuel costs on liner service configuration in container shipping, Journal of Transport Geography 17(5): 325-337. https://doi.org/10.1016/j.jtrangeo.2008.05.003

Pantuso, G.; Fagerholt, K.; Hvattum, L. M. 2014. A survey on maritime fleet size and mix problems, European Journal of Operational Research 235(2): 341-349. https://doi.org/10.1016/j.ejor.2013.04.058

Perakis, A. N.; Jaramillo, D. I. 1991. Fleet deployment optimization for liner shipping. Part 1. Background, problem formulation and solution approaches, Maritime Policy \& Management: the Flagship Journal of International Shipping and Port Research 18(3): 183-200. https://doi.org/10.1080/03088839100000022

Ronen, D. 2011. The effect of oil price on containership speed and fleet size, Journal of the Operational Research Society 62(1): 211-216. https://doi.org/10.1057/jors.2009.169

Schinas, O.; Stefanakos, C. N. 2012. Cost assessment of environmental regulation and options for marine operators, Transportation Research Part C: Emerging Technologies 25: 81-99. https://doi.org/10.1016/j.trc.2012.05.002

Sys, C.; Vanelslander, T.; Adriaenssens, M.; Van Rillaer, I. 2016. International emission regulation in sea transport: Economic feasibility and impact, Transportation Research Part D: Transport and Environment 45: 139-151. https://doi.org/10.1016/j.trd.2015.06.009

Teghem, J.; Pirlot, M.; Antoniadis, C. 1995. Embedding of linear programming in a simulated annealing algorithm for solving a mixed integer production planning problem, Journal of Computational and Applied Mathematics 64(1-2): 91-102. https://doi.org/10.1016/0377-0427(95)00009-7

Vierth, I.; Karlsson, R.; Mellin, A. 2015. Effects of more stringent sulphur requirements for sea transports, Transportation Research Procedia 8: 125-135. https://doi.org/10.1016/j.trpro.2015.06.048

Wang, S.; Meng, Q. 2017. Container liner fleet deployment: a systematic overview, Transportation Research Part C: Emerging Technologies 77: 389-404.

https://doi.org/10.1016/j.trc.2017.02.010

Wang, S.; Meng, Q. 2012. Sailing speed optimization for container ships in a liner shipping network, Transportation Research Part E: Logistics and Transportation Review 48(3): 701-714. https://doi.org/10.1016/j.tre.2011.12.003

Wang, S.; Meng, Q.; Liu, Z. 2013a. Bunker consumption optimization methods in shipping: a critical review and extensions, 
Transportation Research Part E: Logistics and Transportation Review 53: 49-62. https://doi.org/10.1016/j.tre.2013.02.003

Wang, T.; Meng, Q.; Wang, S.; Tan, Z. 2013b. Risk management in liner ship fleet deployment: a joint chance constrained programming model, Transportation Research Part E: Logistics and Transportation Review 60: 1-12.

https://doi.org/10.1016/j.tre.2013.09.001

Wang, C.; Xu, C. 2015. Sailing speed optimization in voyage chartering ship considering different carbon emissions taxation, Computers \& Industrial Engineering 89: 108-115. https://doi.org/10.1016/j.cie.2015.04.034

Xie, X.; Wang, T.; Chen, D. 2000. A dynamic model and algorithm for fleet planning, Maritime Policy \& Management: the Flagship Journal of International Shipping and Port Research 27(1): 53-63. https://doi.org/10.1080/030888300286680

Yang, H.; Ma, X.; Xing, Y. 2017. Trends in $\mathrm{CO}_{2}$ emissions from china-oriented international marine transportation activities and policy implications, Energies 10(7): 980.

https://doi.org/10.3390/en10070980

Yao, Z.; Ng, S. H.; Lee, L. H. 2012. A study on bunker fuel management for the shipping liner services, Computers \& Operations Research 39(5): 1160-1172.

https://doi.org/10.1016/j.cor.2011.07.012

Zhao, F.; Zeng, X. 2006. Simulated annealing-genetic algorithm for transit network optimization, Journal of Computing in Civil Engineering 20(1): 57-68.

https://doi.org/10.1061/(ASCE)0887-3801(2006)20:1(57)

\section{APPENDIX}

In order to solve the proposed model by the DM, we expand this model with all relevant variables as follows:

$$
\begin{aligned}
& \min C=\sum_{v=1}^{m} \sum_{r=1}^{n} 7 \cdot C_{v} \cdot n_{v r} \cdot x_{v r}+ \\
& \sum_{v=1}^{m} \sum_{r=1}^{n}\left(P_{1} \cdot\left(\frac{s_{v r}}{S_{v}^{D}}\right)^{3} \cdot \frac{F_{v}^{D} \cdot\left(L_{r}-L_{r 1}\right)}{24 \cdot s_{v r}}+\right. \\
& P_{3} \cdot\left(\frac{s_{v r}}{S_{v}^{D}}\right)^{3} \cdot \frac{F_{v}^{D} \cdot L_{r 1}}{24 \cdot s_{v r}}+ \\
& \left.P_{2} \cdot F_{v}^{0} \cdot\left(7 \cdot n_{v r}-\frac{L_{r}}{24 \cdot s_{v r}}-T_{r 1}\right)+P_{3} \cdot F_{v}^{0} \cdot T_{r 1}\right) \cdot x_{v r}+ \\
& E \cdot \sum_{v=1}^{m} \sum_{r=1}^{n}\left(A_{1} \cdot\left(\frac{s_{v r}}{S_{v}^{D}}\right)^{3} \cdot \frac{F_{v}^{D} \cdot\left(L_{r}-L_{r 1}\right)}{24 \cdot s_{v r}}+\right. \\
& A_{3} \cdot\left(\frac{s_{v r}}{S_{v}^{D}}\right)^{3} \cdot \frac{F_{v}^{D} \cdot L_{r 1}}{24 \cdot s_{v r}}+ \\
& \left.A_{2} \cdot F_{v}^{0} \cdot\left(7 \cdot n_{v r}-\frac{L_{r}}{24 \cdot s_{v r}}-T_{r 1}\right)+A_{3} \cdot F_{v}^{0} \cdot T_{r 1}\right) \cdot x_{v r}+ \\
& \sum_{v=1}^{m} \sum_{r=1}^{n} \sum_{i=1}^{N_{r}}\left(G_{r i}+O_{r i} \cdot B_{v}\right)
\end{aligned}
$$

subject to:

$$
Y_{r}^{k}<\sum_{v=1}^{m} x_{v r} \cdot B_{v}, \forall r \in R, k \in\left\{1,2, \ldots, N_{r}\right\} ;
$$

$$
\begin{aligned}
& \sum_{v=1}^{m} \sum_{r=1}^{n}\left(A_{1} \cdot\left(\frac{s_{v r}}{S_{v}^{D}}\right)^{3} \cdot \frac{F_{v}^{D} \cdot\left(L_{r}-L_{r 1}\right)}{24 \cdot s_{v r}}+\right. \\
& A_{3} \cdot\left(\frac{s_{v r}}{S_{v}^{D}}\right)^{3} \cdot \frac{F_{v}^{D} \cdot L_{r 1}}{24 \cdot s_{v r}}+ \\
& \left.A_{2} \cdot F_{v}^{0} \cdot\left(7 \cdot n_{v r}-\frac{L_{r}}{24 \cdot s_{v r}}-T_{r 1}\right)+A_{3} \cdot F_{v}^{0} \cdot T_{r 1}\right) \times \\
& x_{v r} \leq U_{e} ; \\
& T_{r}^{s}=\frac{L_{r}}{\sum_{v=1}^{m} 24 s_{v r} \cdot x_{v r}}, \forall r \in R ; \\
& T_{v r}=x_{v r} \cdot\left(T_{r}^{p}+\frac{L_{r}}{24 \cdot s_{v r}}\right), \forall v \in V, r \in R ; \\
& n_{v r}=\left[\frac{\left.T_{r}^{p}+\frac{L_{r}}{24 \cdot s_{v r}}\right], \forall v \in V, r \in R ;}{7}\right\rceil \\
& t_{r}^{a}=\sum_{v=1}^{m}\left(7 \cdot n_{v r}-\frac{L_{r}}{24 \cdot s_{v r}}\right) x_{v r}, \forall r \in R ; \\
& \sum_{r=1}^{n} x_{v r} \cdot n_{v r} \leq N_{v}, \forall v \in V ; \\
& \sum_{v=1}^{m} x_{v r}=1, \forall r \in R ; \\
& S_{v}^{\min } \leq \sum_{r=1}^{n} x_{v r} \cdot s_{v r} \leq S_{v}^{\max }, \forall v \in V ; \\
& n_{v r} \in Z^{+}, \forall v \in V, r \in R .
\end{aligned}
$$

This model is a mixed-integer nonlinear programming model with nonlinear terms in its objective function (1) and constraints (3)-(7). The binary variable $x_{v r}$ increases the complexity of the model. In order to solve this problem, we can first determine which type of containerships is deployed on the route $r$. Due to the decision of the ship type on each route, we remove all the subscripts of containership type $v$ from the parameters and variables. For example, the ship speed $s_{v r}$ of type $v$ on route $r$ can be expressed as $s_{r}$. The above model can be simplified as follows:

$$
\begin{aligned}
& \min C=\sum_{r=1}^{n} 7 \cdot C_{r} \cdot n_{r}+ \\
& \sum_{r=1}^{n}\left(P_{1} \cdot\left(\frac{s_{r}}{S_{r}^{D}}\right)^{3} \cdot \frac{F_{r}^{D} \cdot\left(L_{r}-L_{r 1}\right)}{24 \cdot s_{r}}+\right. \\
& P_{3} \cdot\left(\frac{s_{r}}{S_{r}^{D}}\right)^{3} \cdot \frac{F_{r}^{D} \cdot L_{r 1}}{24 \cdot s_{r}}+ \\
& \left.P_{2} \cdot F_{r}^{0} \cdot\left(7 \cdot n_{r}-\frac{L_{r}}{24 \cdot s_{r}}-T_{r 1}\right)+P_{3} \cdot F_{r}^{0} \cdot T_{r 1}\right)+
\end{aligned}
$$




$$
\begin{aligned}
& E \cdot \sum_{r=1}^{n}\left(A_{1} \cdot\left(\frac{s_{r}}{S_{r}^{D}}\right)^{3} \cdot \frac{F_{r}^{D} \cdot\left(L_{r}-L_{r 1}\right)}{24 \cdot s_{r}}+\right. \\
& A_{3} \cdot\left(\frac{s_{r}}{S_{r}^{D}}\right)^{3} \cdot \frac{F_{r}^{D} \cdot L_{r 1}}{24 \cdot s_{r}}+ \\
& \left.A_{2} \cdot F_{r}^{0} \cdot\left(7 \cdot n_{r}-\frac{L_{r}}{24 \cdot s_{r}}-T_{r 1}\right)+A_{3} \cdot F_{r}^{0} \cdot T_{r 1}\right)+ \\
& \sum_{r=1}^{n} \sum_{i=1}^{N_{r}}\left(G_{r i}+O_{r i} \cdot B_{r}\right)
\end{aligned}
$$

subject to:

$$
\begin{aligned}
& Y_{r}^{k}<B_{r}, \forall r \in R, k \in\left\{1,2, \ldots, N_{r}\right\} ; \\
& \sum_{r=1}^{n}\left(A_{1} \cdot\left(\frac{s_{r}}{S_{r}^{D}}\right)^{3} \cdot \frac{F_{r}^{D} \cdot\left(L_{r}-L_{r 1}\right)}{24 \cdot s_{r}}+\right. \\
& A_{3} \cdot\left(\frac{s_{r}}{S_{r}^{D}}\right)^{3} \cdot \frac{F_{r}^{D} \cdot L_{r 1}}{24 \cdot s_{r}}+ \\
& \left.A_{2} \cdot F_{r}^{0} \cdot\left(7 \cdot n_{r}-\frac{L_{r}}{24 \cdot s_{r}}-T_{r 1}\right)+A_{3} \cdot F_{r}^{0} \cdot T_{r 1}\right) \leq U_{e} ; \\
& T_{r}^{s}=\frac{L_{r}}{24 \cdot s_{r}}, \forall r \in R ; \\
& T_{r}=T_{r}^{p}+\frac{L_{r}}{24 \cdot s_{r}}, \forall r \in R ; \\
& n_{r}=\left[\left(\frac{\left.T_{r}^{p}+\frac{L_{r}}{24 \cdot s_{r}}\right)}{7}\right], \forall r \in R ;\right. \\
& t_{r}^{a}=7 \cdot n_{r}-\frac{L_{r}}{24 \cdot s_{r}}, \forall r \in R ; \\
& \sum_{r=1}^{m} x_{v r} \cdot n_{r} \leq N_{v}, \forall v \in V ; \\
& S_{r}^{\min } \leq s_{r} \leq S_{r}^{\max }, \forall r \in R ; \\
& n_{r} \in Z^{+}, \forall r \in R .
\end{aligned}
$$

It should be pointed out that there is a quantitative constraint on each type of containerships, so constraint (20) contains the subscripts of containership type $v$. It is obvious that both the objective function and the constraints contain the reciprocal of ship speed $s_{r}$ as the main factor that causes the non-linearization of the model. We define new decision variables: $w_{r}=\frac{1}{s}, \forall r \in R$ and let $W_{r}^{\min }=\frac{1}{S_{r}^{\max }}$ and $W_{r}^{\max }=\frac{1}{S_{r}^{\min }} . T_{r}^{S_{r}}$ Thefore, the above model can be expressed as follows:

$$
\begin{aligned}
& \min C=\sum_{v=1}^{m} \sum_{r=1}^{n} 7 \cdot C_{r} \cdot n_{r}+ \\
& \sum_{r=1}^{n}\left(P_{1} \cdot\left(S_{r}^{D}\right)^{-3} \cdot \frac{F_{r}^{D} \cdot\left(L_{r}-L_{r 1}\right) \cdot w_{r}^{-2}}{24}+\right.
\end{aligned}
$$

$$
\begin{aligned}
& \frac{P_{3} \cdot\left(S_{r}^{D}\right)^{-3} \cdot F_{r}^{D} \cdot L_{r 1} \cdot w_{r}^{-2}}{24}+ \\
& \left.P_{2} \cdot F_{r}^{0} \cdot\left(7 \cdot n_{r}-\frac{L_{r} \cdot w_{r}}{24}-T_{r 1}\right)+P_{3} \cdot F_{r}^{0} \cdot T_{r 1}\right)+ \\
& E \cdot \sum_{r=1}^{n}\left(A_{1} \cdot\left(S_{r}^{D}\right)^{-3} \cdot \frac{F_{r}^{D} \cdot\left(L_{r}-L_{r 1}\right) \cdot w_{r}^{-2}}{24}+\right. \\
& \frac{A_{3} \cdot\left(S_{r}^{D}\right)^{-3} \cdot F_{r}^{D} \cdot L_{r 1} \cdot w_{r}^{-2}}{24}+ \\
& \left.A_{2} \cdot F_{r}^{0} \cdot\left(7 \cdot n_{r}-\frac{L_{r} \cdot w_{r}}{24}-T_{r 1}\right)+A_{3} \cdot F_{r}^{0} \cdot T_{r 1}\right)+ \\
& \sum_{r=1}^{n} \sum_{i=1}^{N_{r}}\left(G_{r i}+O_{r i} \cdot B_{r}\right)
\end{aligned}
$$

subject to:

$$
\begin{aligned}
& Y_{r}^{k}<B_{r}, \forall r \in R, k \in\left\{1,2, \ldots, N_{r}\right\} \\
& \sum_{r=1}^{n}\left(\frac{A_{1} \cdot\left(S_{r}^{D}\right)^{-3} \cdot F_{r}^{D} \cdot\left(L_{r}-L_{r 1}\right) \cdot w_{r}^{-2}}{24}+\right. \\
& \frac{A_{3} \cdot\left(S_{r}^{D}\right)^{-3} \cdot F_{r}^{D} \cdot L_{r 1} \cdot w_{r}^{-2}}{24}+ \\
& \left.A_{2} \cdot F_{r}^{0} \cdot\left(7 \cdot n_{r}-\frac{L_{r} \cdot w_{r}}{24}-T_{r 1}\right)+A_{3} \cdot F_{r}^{0} \cdot T_{r 1}\right) \leq U_{e} ; \\
& T_{r}^{s}=\frac{L_{r} \cdot w_{r}}{24}, \forall r \in R ; \\
& T_{r}=T_{r}^{p}+\frac{L_{r} \cdot w_{r}}{24}, \forall r \in R ; \\
& n_{r}=\left[\frac{\left.\left.T_{r}^{p}+\frac{L_{r} \cdot w_{r}}{24}\right)\right], \forall r \in R}{7}\right\rceil \\
& t_{r}^{a}=7 \cdot n_{r}-\frac{L_{r} \cdot w_{r}}{24}, \forall r \in R ; \\
& \sum_{r=1}^{m} x_{v r} \cdot n_{r} \leq N_{v}, \forall v \in V ; \\
& W_{r}^{\min } \leq w_{r} \leq W_{r}^{\max }, \forall r \in R ; \\
& n_{r} \in Z^{+}, \forall r \in R .
\end{aligned}
$$

Though nonlinear constraints (16)-(19) are transformed into linear constraints, this model is still a mixedinteger nonlinear programming model. The objective function (23) and constraint (25) have nonlinear terms owing to the new decision variables $w_{r}, r \in R$. If each $w_{r}$ is given a specific value, all the nonlinear terms could become linear. Therefore, we discretize the decision variables $w_{r}$ at a certain interval and choose one of them for each route. The discretization value of $w_{r}$ should correspond to the ship speed $s_{r}$, because the value of $s_{r}$ is of practical significance. Usually, the optimization results of ship 
speed retain to the first decimal place in the unit of knots (Wang, Meng 2012; Ronen 2011). Thus, the range of $s_{r}$ can be divided into $Q_{r}$ segments at 0.1 knot intervals. The number of segments on route $r$ is $Q_{r}=\frac{S_{r}^{\max }-S_{r}^{\min }}{0.1}$. Then, there are $Q_{r}+1$ values of $s_{r}$ and $w_{r}$. The variable $w_{r}$ can be represented by $w_{r 0}, w_{r 1}, \ldots, w_{r Q_{r}}$, so $w_{r 0}=W_{r}^{\min }$ and $w_{r Q_{r}}=W_{r}^{\max }$. To indicate which ship speed to adopt, we define binary variable:

$$
\begin{aligned}
& \eta_{r q}=\left\{\begin{array}{l}
1, \text { when } w_{r}=w_{r q} \\
0, \text { when } w_{r}=w_{r q}
\end{array}\right. \\
& r \in R, q \in\left\{1,2, \ldots, Q_{r}\right\} .
\end{aligned}
$$

Then, the above model can be transformed into an equivalent integer programming model as follows:

$$
\begin{aligned}
& \min C=\sum_{r=1}^{n} 7 \cdot C_{r} \cdot n_{r}+ \\
& \sum_{r=1}^{n}\left(P_{1} \cdot\left(S_{r}^{D}\right)^{-3} \cdot F_{r}^{D} \cdot\left(L_{r}-L_{r 1}\right) \cdot \sum_{q \in\left\{1,2, \ldots, Q_{r}\right\}} \frac{\eta_{r q} \cdot w_{r q}^{-2}}{24}+\right. \\
& P_{3} \cdot\left(S_{r}^{D}\right)^{-3} \cdot F_{r}^{D} \cdot L_{r 1} \cdot \sum_{q \in\left\{1,2, \ldots, Q_{r}\right\}} \frac{\eta_{r q} \cdot w_{r q}^{-2}}{24}+ \\
& \left.P_{2} \cdot F_{r}^{0} \cdot\left(7 \cdot n_{r}-L_{r} \cdot \sum_{q \in\left\{1,2, \ldots, Q_{r}\right\}} \frac{\eta_{r q} \cdot w_{r q}}{24}-T_{r 1}\right)+P_{3} \cdot F_{r}^{0} \cdot T_{r 1}\right)+ \\
& E \cdot \sum_{r=1}^{n}\left(A_{1} \cdot\left(S_{r}^{D}\right)^{-3} \cdot F_{r}^{D} \cdot\left(L_{r}-L_{r 1}\right) \cdot \sum_{q \in\left\{1,2, \ldots, Q_{r}\right\}} \frac{\eta_{r q} \cdot w_{r q}^{-2}}{24}+\right. \\
& A_{3} \cdot\left(S_{r}^{D}\right)^{-3} \cdot F_{r}^{D} \cdot L_{r 1} \cdot \sum_{q \in\left\{1,2, \ldots, Q_{r}\right\}} \frac{\eta_{r q} \cdot w_{r q}^{-2}}{24}+ \\
& \left.A_{2} \cdot F_{r}^{0} \cdot\left(7 \cdot n_{r}-L_{r} \cdot \sum_{q \in\left\{1,2, \ldots, Q_{r}\right\}} \frac{\eta_{r q} \cdot w_{r q}}{24}-T_{r 1}\right)+A_{3} \cdot F_{r}^{0} \cdot T_{r 1}\right)+ \\
& \left.\sum_{r=1}^{n} \sum_{i=1}^{N_{r}}\left(G_{r i}+O_{r i} \cdot B_{r}\right) \sum_{i}\right)
\end{aligned}
$$

subject to:

$Y_{r}^{k}<B_{r}, \forall r \in R, k \in\left\{1,2, \ldots, N_{r}\right\}$

$$
\begin{aligned}
& \sum_{r=1}^{n}\left(A_{1} \cdot\left(S_{r}^{D}\right)^{-3} \cdot F_{r}^{D} \cdot\left(L_{r}-L_{r 1}\right) \cdot \sum_{q \in\left\{1,2, \ldots, Q_{r}\right\}} \frac{\eta_{r q} \cdot w_{r q}^{-2}}{24}+\right. \\
& A_{3} \cdot\left(S_{r}^{D}\right)^{-3} \cdot F_{r}^{D} \cdot L_{r 1} \cdot \sum_{q \in\left\{1,2, \ldots, Q_{r}\right\}} \frac{\eta_{r q} \cdot w_{r q}^{-2}}{24}+ \\
& \left.A_{2} \cdot F_{r}^{0} \cdot\left(7 \cdot n_{r}-L_{r} \cdot \sum_{q \in\left\{1,2, \ldots, Q_{r}\right\}} \frac{\eta_{r q} \cdot w_{r q}}{24}-T_{r 1}\right)+A_{3} \cdot F_{r}^{0} \cdot T_{r 1}\right) \leq U_{e} ;
\end{aligned}
$$$$
T_{r}^{s}=L_{r} \cdot \sum_{q \in\left\{1,2, \ldots, Q_{r}\right\}} \frac{\eta_{r q} \cdot w_{r q}}{24}, \forall r \in R
$$

$$
T_{r}=T_{r}^{p}+L_{r} \cdot \sum_{q \in\left\{1,2, \ldots, Q_{r}\right\}} \frac{\eta_{r q} \cdot w_{r q}}{24}, \forall r \in R
$$

$n_{r} \leq\left[\frac{T_{r}^{p}+L_{r} \cdot \sum_{q \in\left\{1,2, \ldots, Q_{r}\right\}} \frac{\eta_{r q} \cdot w_{r q}}{24}}{7}\right], \forall r \in R$;

$t_{r}^{a}=7 \cdot n_{r}-L_{r} \cdot \sum_{q \in\left\{1,2, \ldots, Q_{r}\right\}} \frac{\eta_{r q} \cdot w_{r q}}{24}, \forall r \in R ;$

$\sum_{r=1}^{m} x_{v r} \cdot n_{r} \leq N_{v}, \forall v \in V$

$\sum_{q \in\left\{1,2, \ldots, Q_{r}\right\}} \eta_{r q}=1, \forall r \in R$;

$\eta_{r q}=\{0,1\}, \forall r \in R, q \in\left\{1,2, \ldots, Q_{r}\right\} ;$

$n_{r} \in Z^{+}, \forall r \in R$.

Constraint (41) indicates that only one single ship speed value is adopted to each liner route. Finally, the transformed model can be efficiently solved by the optimization solver such as CPLEX. 